\section{UK government research}

SIR - I should like to add to your Commentary "How will Britain run its science now?" (Nature 361, 581-584; 1993) one additional point that I think is worth making about government research. It is important to distinguish research that is undertaken by departments in order to fulfil their prime functions (for example the Ministry of Defence, the Department of Health, Transport and so on), from research that is sponsored for the broader national good by departments such as the Department for Education, the Department of Trade and Industry and the Office of Science and Technology, the results of that research being primarily of interest to others.

Departments of the first kind may be expected - like major international research-dependent companies - to do no more research than is necessary to fulfil their missions. As an example, the Ministry of Defence research programme is focused on government defence objectives and is, therefore, weighed against other priorities in the defence budget. The aim is to find the right balance between research and other elements such as personnel, equipment, training and so on, and the implication is that if the research spend were different from what is finally agreed, the country would get less good value for money in defence. In consequence, the scale of research spend of 'research-user departments' can be expected to reflect government objectives for those departments, spend.

Ronald Oxburgh

(Chief Scientific Adviser)

Ministry of Defence,

Main Building,

Whitehall,

London SW1A 2HB, UK rather than to comprise any particular proportion of the national research

These issues are, however, separate from that of how the country should best go about deriving as much secondary benefit as possible from research that the 'user departments' carry out, whether through collaboration, coordination of related work of different sponsors, or disseminating results outside government. UK government departments and universities alike have had initiatives to promote commercial exploitation of work from their laboratories; few, however, are totally content with what they have achieved and we have seen good ideas unexploited, or exploited abroad - liquid crystals that find a hundred-and-one day-to-day applications were developed at the former Royal Signals and Radar Research Establishment at Malvern but turned into a commercial product by the Japanese. It is in this area that we have to find some different way of managing our affairs.

SIR - Although much of the support for science, from the public or private sectors, must clearly be for science with an application in mind, it is essential that there should be adequate funds (wholly

\section{Countering the calories}

SIR - With his usual perspicuity, Daedalus has pointed out (Nature 360, 112 ; 1992) the way to solving the relatively affluent's dilemma of I-don'twant-to-be-fat but I-do-want-to-eat.

He neglected to mention - probably for commercial considerations - the real reasons why dinitrophenol is the compound his researchers are almost certainly derivatizing right now, seeking the permutation that retains all its desirable traits while eliminating its undesirable ones.

The billion-dollar diet-aid potential of dinitrophenol derivatives (DNDs), of course, lies in the parent compound's biochemical role as a decoupler of oxidative phosphorylation. The mitochondria, quite sensibly evolutionarily speaking, tightly link the burning of food to the creation of ATP and, if this is not used up, the furnace shuts down and the food gets shunted off to the fat reserves.

Carefully tailored for organ and metabolic specificity, the DNDs will circumvent this now-disadvantageous coupling and allow the Krebs' cycle to spin uselessly, converting unwanted calories to heat and carbon dioxide.

The commercial potential of DND rivals that of sugar and fat. It could, for instance, be premixed into fast-foods, dramatically reducing their calorific impact and increasing their consumerability. The cultural impact would also be sublime: the potential of sprinkling a meal of 2,000 calories down to just 15 would quickly clear restaurants of dinky starvation rations and reawaken an interest in the butter-saturated cooking of a bygone era.

I await the commercial introduction of DND with the interest only to be expected of a 15-pound overweight chap who cannot wait to resign from the self-imposed torture and tedium of his health club.

\section{RIchard L. Lewis}

4 West 43rd Street,

Apt 517,

New York,

New York 10036, USA or largely provided by government) for curiosity-directed research. This is a cultural requirement, just as public support for the arts is. The amount provided needs to be secure, and the only objective in its disbursement should be to help create the best science possible.

Wherever given funds are employed to create science, whether basic or applied, the division of funds between supporting scientists on the one hand and equipping them on the other must be governed by the need to get the best science for the sums supplied. Inability to fund good proposals is a clear sign that, for the money available in the field in question, there are too many scientists working in it. Fruitlessly chasing funds is an inefficient use of scientists' time.

As there is good reason to suppose that in many fields the cost of properly supporting a scientist with equipment is growing faster than the funds likely to be available, it follows that in any such field the number of working scientists should diminish year by year. It may be difficult to attain the optimum numbers in a field, but the objective of matching the numbers to funds available should be kept firmly in mind. Failure to do so is unfair to the provider of funds, and bad for science.

Where researchers are supported because of the prospective benefit to British industry, it is essential to ensure that companies are in a position to exploit a research success. A repetition of the liquid crystal fiasco would be hard to accept.

It is important to have a system that can take account of the basic differences between applied sciences such as engineering and the fundamental sciences such as chemistry and physics. For many of the ablest pure-science undergraduates, research in their field is the principal ambition, whereas many of the ablest engineering undergraduates aim to practise engineering as soon as possible. Thus whereas in science one can expect to fill a research studentship with the highest level of graduate, this cannot be taken for granted in engineering.

The weakness of the connection between defence and civil research and development is particularly noticeable in Britain, as the recent POST report made clear. One would hope that at least a beginning can be made on bridging this gap.

The forthcoming White Paper will address questions of organization. It is important that the bureaucracy should be aware of the needs of the working researchers. In particular, those disbursing funds must visit the laboratories where the work is actually being done. 